\title{
MEGANISISME, VITALISME EN HOLISME IN DIE BIOLOGIE
}

Die Biologie word omskryf as die wetenskap van dic lewende wesens (organismes). Die lewe staan dus in die hrandpunt van die biologiese studie en ondersoek. Vra ons ons egter af wat onder "lewe" verstaan word, besef ons dadelik dat ons hier met ' $n$ uiters moeilik definieerbare begrip tc doen het. In verband met die aard van lewe het daar ondes die bioloë en natuurfilosowe veral twee denkrigtings posgevat, nl. meganisisme en vitalisme.

Lotze en Sihler (1954) beweer dat die geskiedenis van die Biologie wesentlik niks anders is as die geskiedenis van die stryd tussen meganisisme en vitalisme nie. Volgens hulle was Leukippos en Demokritos uitgesproke meganisiste, terwyl Aristoteles 'n vitalis was. Gedurende die Middelecue het laasgenoemde se opvattings die botoon gevoer, en selfs aan dir drempel van dic nuwe tyd vind ons hulle by 'n gelecrde soos Paracelsus. Met die Renaissance, toe die induktiewe metode in die natuurwetenskap ingevoer is, het daar in dié opsig, soos in vele andere, 'n wending gekom. Dit het daartoe gelei dat pogings aangewend is om die lewe bloot op grond van stoflikmeganiese beginsels te verklaar. Die meganisistiese idee het spoedig by baie bioloë inslag gevind, hoewel daar nog steeds diegene was wat die vitalisme aangehang het.

\section{Die meganisisme:}

Volgens Von Bertalanffy (1932 en 1949) was dit eintlik dic groot Franse filosoof Descartes $(1596-1650)$ wat die meganisisme in dic natuurwetenskap ingevoer het. Hy het naamlik teen die middel van die 17 e eeu die legrip van die sogenaamde bête machine (masjiendier) gepostuleer, waarvolgens 'n organisme as 'n masjien beskou moet word wat, hoewel dit haie ingewikkelder saamgestel is, tog vergelyk kan word met 'n masjien wat deur die mens vervaardig is. 
As gelowige lidmaat van die Rooms-Katolieke Kerk het hy egter 'n grens getrek vir die toepassing van hierdie begrip, nl. by die mens. Omdat die mens 'n vrye wil besit, is dit volgens hom nie aan die gewone natuurwette onderworpe nie. Hierdie grenslyn is deur die Aufklärung uitgewis. De la Mettrie het naamlik in 1748 die begrip homme machine (masjienmens) naas Descartes se bête machine gestel. Daardeur is alle organismes, insluitende die mens, as hoogs ingewikkelde masjiene beskou wat eenvoudig deur die kousaliteitswette van die lewelose natuur beheer word en wat deuı geen besondere kragte of vermoëns van die anorganiese wêreld onderskei kan word nie.

Hierdie meganisistiese opvatting van organismes het deur die daaropvolgende ontdekkings, veral van die $19 \mathrm{e}$ eeu, steed: meer en meer veld gewin en 'n groot houvas op die biologiese denke verkry. Behalwe bogenoemdes was o.a. die volgende aanhangers van een of ander vorm van die meganisisme: Hobbes, Spinoza, Fries, Lotze, Moleschott, Spencer, Du BoisReymond, Darwin, Haeckel, Loeb, Ostwald en J. Schulz. Spencer het bv. die lewe as 'n aanpassing by inwendige en uitwendige toestande beskou, terwyl Schultz gemeen het dat die finale en doelmatige in die lewensverskynsels in die struktuur of sogenaamde biogene geplaas kan word wat sedert alle ewigheid as "Typovergenzmaschinen" bestaan.

Die meganisisme is dikwels in die sin van "masjienteorie" verklaar, d.w.s. daar is gemeen dat die lewende strukture as blote masjiene opgeneem moet word. Ander meganisiste het egter hetoog dat 'n organisisme 'n meganisme kon wees, sonder om noodwendig 'n masjien te wees. Volgens hulle is die organisme die produk van fisiese en chemiese kragte en moet dit as 'n meganisme of chemisme van uiters gekompliseerde aard beskou word wat van die anorganiese wêreld nie fundamenteel verskillend is nie. Alle lewensverskynsels moet tot die fisiese en chemiese wetmatighede van die anorganiese natuur teruggevoer word, en daar is slegs een kategoorie waarvolgens die lewe verklaar kan word, nl. kausaliteit. Die verskynsel doelmatigheid, wat so treffend by organismes tevoorskyn tree, beskou die meganisis slegs as 'n heuristiese heginsel; volgens hom verklaar dit niks nie, maar moet self 
verklaar word; dit dui prohleme aan maar gee nie hulle oplossing nie.

Nou verbonde met die meganisisme is die materialistiese evolusionisme. In sy radikale vorm trag die evolusionisme om fisies-kousale verklarings te gee vir alle probleme in verband met die ontstaan van die lewe en die ontwikkeling daarvan tot die veelheid van lewensvorms wat aan ons bekend is. Die radikale evolusioniste is aanhangers van die generatio spontanea-gedagte, d.w.s. die opvatting dat die eerste organismes op 'n bloot meganiese wyse spontaan uit lewelose stowwe ontstaan het. So bv. sê die bekende evolusionis Huxley (1949): „I have always believed ... in the natural origin of the living from non-living matter on this planet", terwyl Simpson (1952) heweer: „There is, at any rate, no reason to postulate a miracle. Nor is it necessary to suppose that the origin of the new processes op reproduction and mutation was anything but materialistic. That is, study of these basic functions of existing organisms tends strongly to support the view that the novelty lies only in the organization or state of matter and its surroundings and not in the rise of any new property or principle, physical or non-physical. Once this point is established the origin of life is stripped of all real mystery..."

Die verandering en ontwikkeling van organismes asook die doelmatigheid van die lewensverskynsels word deur dic radikale evolusioniste toegeskryf aan toevallige, erflike veranderings (mutasies) en daaropvolgende natuurlike seleksie in die stryd om die hestaan. Daar word streng aan die stofliike vasgehou en die natuur word slegs uit die natuur verklaar.

Sowel die meganisisme as die radikale evolusionisme is eintlik uitvloeisels van die materialisme, d.w.s. van dié denkrigting wat eerstens die idee huldig dat alles in die heelal uiteindelik herleibaar is tot dinge wat stoflik van aard is, en tweedens meen dat alles in die natuur onderworpe is aan die fisies-kousale wette wat die stoflike dinge beheer (Joad, 1948, p. 497).

\section{Die vitalisme:}

Regstreeks teenoor die meganisisme staan dic vitalisme, wat beweer dat die lewe nie resloos en bevredigend uit die stoflike 
en op grond van die lisies-kousale wetmatigheid verklaar kan word nie.

a) Die ou vitalisme. Die vitalisme het sy oorsprong in die sogenaamde animisme van Aristoteles. Hy het die opvatting gehuldig dat alle lewende wesens 'n siel het en dat die siel die eintlike lewensheginsel is wat aan die liggaam lewe verleen. Die siel is die beginsel van voeding en voortplanting (plantelewe), van persepsie (dierelewe) en van denke (menselewe). Die aanhangers van die skolastisisme was 'n soortgelyke idee toegedaan. Paracelsus (1439-1541), Van Helmont (1577 ....1649) e.a. het geglo aan sielagtige, onbewus-doelmatige lewensheginsels, terwyl Leibnitz (1646-1716) die bestaan van lewenskragte, wat in die fisiese gebeure ingryp, verwerp het, en daarteenoor sy opvatting in verband met die sogenaamde "monades" gestel het. Volgens hierdie opvatting is die hele universum vol lewe, al is dit onsigbaar. Die kleinste materiedeeltjies is nie dooie atome nie, maar lewende „monades". Die menslike siel is 'n monade met bewussyn. Die aktiwiteit van die monades bestaan verder nie in beweging nie, maar in krag. Die monades word deur die wette van die harmoniese, kosmiese orde beheers, wat deur God as die hoogste monade geskep is.

Uit hierdie animisme het die vitalisme voortgevloei, wat die lewe tot 'n besondere "lewenskrag" (,vis vilalis") of "lewenstof" teruggevoer het. Die lewenskrag sou die eintlik wesentlike van die lewe wees wat organiserend, regulerend en doelmatig optree en wat die fisikalies-chemiese kragte in die organisme aanwend, lei en rig. 'n Sodanige vitalisme is o.a. deur die volgende gehuldig: die mediese skool van Montpellier, $\Lambda$. von Haller (1707-1777), Blumenbach (1752-1840), Reil (1759-1813), Goethe (1749-1832), $\Lambda$. von Humboldt, 1769) -1859; later nie meer nie!) en Joh. Müller (1801-1858). Volgens Schopenhauer $(1788-1860)$ is die lewenskrag niks anders as „wil" nie, terwyl daar volgens Liebig (1803-1873) slegs ' $n$ vormsbouende beginsel in en saam met die fisiese en cheniese kragte voorkom. Claude Bernard (1813-1878) praat van 'n „vitale invloed" en 'n ,organiese plan" terwyl 0 . Liebmann melding maak van 'n "raaiselagtige plus" wat tot die meganisme cn chemisme toetree.

Hierdie onere vitaliste was daarvan oortuig dat die we- 
sentlike trekke van die lewe nie tot die lewelose teruggevoci kan word nie, maar wel tot 'n vitale faktor wat, soos reeds aangedui, gewoonlik as 'n besondere lewenskrag beskou is. So bv. het sommige onder die ouere vitaliste geglo dat dic Fisika en die Skeikunde nooit daarin sou slaag om organiese stowwe sinteties voort te bring nie. Hulle het sodanige stowwe as kenmerkend van organismes en organismes alleen beskou. Toe Wöhler in 1828 egter daarin geslaag het om ureum sinteties te berei, en die organiese skeikunde kort daarna geweldig opgang begin maak het, sodat daar naderhand 'n groot aantal organiese verbindings bekend was, wat sinteties in die laboratorium berei kon word, moes hierdie idee prysgegee word. Ook sekere ander lewensverskynsels, wat die vitaliste aan hul „lewenskrag" toegeskryl het, is later op 'n ander wyse met hehulp van die Fisika en Skeikunde hevredigend verklaar, en daardeur is baie gevoelige slae aan die vitalisme toegedien. Baie van die opvattings van die ouere vitaliste het gevolglil: naderhand heeltemal onhoudbaar geword, en daarmee het die meganisisme aansienlik veld gewen.

b) Die neovitalisme: Die sogenaamde neovitalisme (wat vir die eerste keer in 1856 deur Virchow onderskei is) het as reaksie teen die streng meganistiese biologie tevoorskyn getree. Hierdie gedagterigting beklemtoon die outonomie van die lewe, die eiewetmatigheid daarvan, die eiesoortigheid van die organiese vorm en funksie en die doelstrewige en doelmatige werksaamheid van die organiese potensies, energieë en rigkragte. Volgens die vitalisme kan die lewe nie afdoende en resloos uit bloot fisies-chemiese prosesse of wette afgelei word nie, en kan die doelmatige gestaltes en funksies van organismes ook nie meganisties-kousaal begryp word nie. As verteenwoordigers van die neovitalisme kan genoem word Rindfleisch ( liche Philosophie 1883; Neovitalismus, 1895), G. Bunge (Vitalismus und Mechanismus, 1886), O. Hertwig (Mechanik und Biologie, 1897), Rádl, J. von Uexküll en Hans Driesch. Ek gee hier slegs kortliks die idees van Rádl en Von Uexküll om daarna meer bepaald die aandag op Driesch te vestig.

Rádl het bekend geword vanweë sy jdees in verband met die sogenaamde ideële morfologie. Die Darwinistiese morlologie het hy veroordeel as 'n geestelose beskrywing en aanmekarvoeging van die verskillende ontwikkelingsvorms. Hy 
meen dat die doel van die morfologie moet wees die soek na idees waarvolgens die vorms van lewende organismes gebou is. $\mathrm{Hy}$ het beweer dat daar ,aan die wortel van organiese lewe verskillende idees om voorrang veg; aan elke organisme lê daar 'n ideële struktuur ten grondslag". As getuienis vir hier. die opvatting haal hy o.a. sy eie waarnemings in verband met die sentrale senuweestelsel aan, wat vir die wetenskap onaan. vaarbaar is. Daar is dan ook nie veel waarde aan sy spekulasies geheg nie - hulle het eerder verwondering opgewek omdat hulle so fantasties en in stryd met erkende wetenskaplike reite was.

Jacob von Uexküll se opvatting kom daarop neer dat slegs 'n gedeelte van die lewensverskynsels meganies bepaalhaar en verstaanbaar is, terwyl die ander gedeelte bo die meganiese vlak geleë is; en dit is juis laasgenvemde gedeelte wat volgens hom aan die meganiese prosesse doelgerigtheid gee. Die bomeganiese lewensverskynsels moet volgens hom teruggevoer word tot die impulse van 'n planmatige natuurkrag. Hierdie natuurkrag kleef op een of ander onbekende wyse aan die protoplasma en verwesenlik as rigtinggewende (,lenkende") faktor die „ontstaanreëls" van die organisme. Reeds by die eenselliges tree dit as rigtinggewende faktor op deurdat dit die vorming en vernietiging van organe volgens die behoefte van die organisme reguleer. In hoër organismes tree dit in al die regulerende prosesse op, en by egte handelinge gryp dit by die sentrale senuweestelsel in. Die rigtinggewende faktor is wyser as wat die dier self bewustelik is; dit ken die wettelikheid van die wêreld wat die dier self nie ken nie; dit bewerkstellig die inpassing van die dier in dis wêreld. (In plaas van die gebruiklike term ,aanpassing” praat hy van ,inpassing” („Einpassung”)).

Von Uexküll het ongetwyfeld reg in sy bewering dat die lewe nie geheel en al meganisties verklaar kan word nie. Die planmatige natuurkrag wat as rigtinggewende faktor optree, is egter ' $n$ baie vae begrip in verband waarmee daar geen sekerheid bestaan nie.

Onder die neovitaliste is Driesch sekerlik die belangrikste figuur. Volgens M. Hartmann (1933 en 1956) is Driesch se opvattings die enigste vitalisme wat ernstig opgeneem kan word. Net soos die meganisiste verwerp Driesch die ouere vita- 
liste se opvattings in verband met die bestaan van 'n lewenskrag. Hy is egter daarvan oortuig dat die lewe nie bloot fisieschemies verklaar kan word nie, maar aan 'n eie soort kousaliteit onderworpe is wat hy as ,geheelheidskousaliteit" ("Ganzheitskausalität"), naas die meganistiese "enkel-kousaliteit" (,Einzelkausalität") stel. Hy meen dat daar in die organisme 'n onbekende, nie-ruimtelike faktor(e) werksaam is wat die stoflike gebeure reël en beheer, sodat die lewensprosesse nie in enige rigting verloop nie, maar steeds sodanig dat hulle tot die totstandkoming en behoud van die geheel lei. In aansluiting by Aristoteles het hy hierdie onbekende faktor(e)

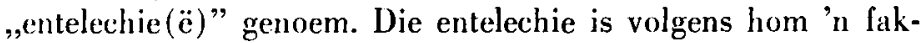
lor van nie-ruimtelike en nie-energetiese aard; dit kan nie energie voortbring of vermeerder nie, maar het slegs 'n rigtinggewende ("lenkende") funksie. Net soos die mens sy dooie masjiene kan beheer en rig, so beheer en rig die entelechie dic lewelose, stoflike in die organisme, sonder om daarby die twee hoofwette van die termodinamika te skend (Driesch, 19221

Vir sy opvatting dat die lewe nie op 'n bloot fisies-chemiese grondslag verklaar kan word nie, maar outonoom is en deur vitale faktore beheer word, voer Driesch drie bewyse aan, naamlik i) die wat op die analise van die differensiëring van harmonies-ekwipotensiale sisteme berus (bv. see-egeleiers); ii) die wat op die verskynsels van erflikheid en eiervorming berus; en iii) die wat op die handelinge van diere berus. (Op die besonderhede van hierdie "hewyse" sal ek nie ingaan nie. Hartmann (1925, 1933, 1948 en 1956) toon oortuigend aan dat Driesch se bewyse nie aanvaarbaar is nie, hoofsaaklik omdat hy hulle bou op sekere prinsipiële uitgangspunte in verband met die meganisisme wat nie korrek is nie. So bv. voer hy aan dat die eiers in die moederorganismes deur deling van die oereiersel ontstaan en stel dan die vraag: hoe kan so 'n saamgestelde struktuur gedurig deel en sy geheelheidskarakter behou, as dit'n masjien is? Vir hom is so iets ondenkbaar en daarom verwerp hy die meganisistiese opvatting. Die moderne navorsing het egter hewys dat so iets wel moontlik is. Volgens die chromosoomteorie van die erflikheid is daas by die kerndeling 'n deling van die chromosome betrokke, en die dogterchromosome, wat op 'n reëlmatige wyse tussen die 
gevormde dogterselle verdeel word, hevat al die erflikheidsfaktore van die moedersel; die geheelheid van die struktuur word daardeur behou.

Hartmann (1933) wys ook op 'n aantal verdienstelikhede van Driesch se opvatting. In die eerste plek stel Driesch se formulering van die vitalisme geen hindernisse in die weg van die kousale ondersoek nie; in teenstelling met ander vitaliste meen hy dat vitale faktore nie in die meganisme van die kousaliteit self ingryp nie. In die tweede plek het Driesch ongetwyfeld reg as hy te velde trek teen 'n meganisistiese dogmatisme wat dikwels in die opklaar van 'n gedeeltelike oorsaak die oplossing van die hele probleem sien. Trouens, die groot verdienste van die vitalisme in die algemeen is sekerlik geleë in sy kritiek op die meganisisme; in sy opvattiing dat die wesentlike van die lewe nie op 'n bloot fisies-chemiese grondslag verklaar kan word nie. Driesch het sekerlik reg waar hy met alle nadruk op die bestaan van groot onopgeloste vraagstukke in die Biologie wys. Hartmann meen dat daaraan toegevoeg kan word dat die biologiese probleme in hul geheelheid en volheid nie heeltemal rasionaliseerbaar is nie, d.w.s. nie heeltemal deur die kategorie van die kousaliteit "gevat" kan word nie. Hy meen egter dat die „irrasionele" (bo-redelike) nie 'n spesifieke kenmerk van organismes is nie, maar in elke voorwerp skuil. Driesch en die ander vitaliste trek volgens hom die grens van die kenbare op 'n verkeerde plek, nl. tussen die organiese en die anorganiese, terwyl dit in werklikheid tussen die „rasionele" (redelike) en die ,irrasionele" (boredelike) lê.

Hartmann (1933) wys verder daarop dat die natuurwetenskap met die sogenaamde "buite-ruimtelike natuurfaktore" of „entelechieë" niks kan aanvang nie. Met hierdie begrippe kan prinsipieel geen natuurwetenskaplike kennis ingewin word nie. $\mathrm{Na}$ aanleiding van Weyl se bewering: „Die Philosophen sind ungeduldige Leute", beskuldig Hartmann die vitaliste daarvan dat hulle nie geduld het om die langsame weg van navorsing te volg nie, en daarom voer hulle beginsels soos „entelechie", geheelheid en planmatigheid in. Al het Driesch sy teorie met groot skerpsinnigheid en strenge logika ontwik. $\mathrm{kel}$, is dit tog nie vir die vooruitgang van die natuurwetenska! soveel werd soos die geduldige en noukeurige navorsing a 
analise van kleinere probleme nie. Selfs al sou daar in die organisme nie-ruimtelike faktore of ,entelechiee" werksaam wees, is dit vir die mens nie moontlik om dit te bewys nie, want ons kan ons natuurwetenskaplike kennis slegs met die kategorie van die kousaliteit inwin - aldus Harmann (1933 en 1956).

Lotze en Sihler (1954) neem in hulle bespreking van die meganisisme-vitalisme-probleom 'n soortgelyke standpunt in. Hulle meen dat dit op 'n natuurwetenskaplike grondslag nie moontlik en toelaatbaar is om te sê of die lewe deur nie-ruimtelike faktore beheers word nie, omdat ons dit nooit sal kan hewys nie. Wat die mens nie op een of ander wyse kan ,vat" nie, hoort nie in die natuurwetenskap tuis nie, is irrasioneel en daarom 'n deel van die Metafisika. Die dogmatiese vitalisme is derhalwe 'n metafisiese leerstelling. Hulle meen egter dat die dogmatiese meganisisme 'n soortgelyke gebrek vertoon as dit heweer dat daar behalwe die verskynsels wat deur die kousaliteit hepaal word, geen ander verskynsels in die natuur voorkom of kan voorkom nie. Daarmee beweer dit meer as wat dit kan of mag sê, en word gevolglik 'n negatiewe Metafisika. Sowel die meganisisme as die vitalisme is derhalwe volgens hulle metafisiese beskouings of geloofsbekentenisse wat nie in die naturwetenskap tuishoort nie, maar wel in die natuurfilosofie.

\section{Holisme:}

Volgens hierdie denkrigting moet die geheelheidskarakter van alle dinge as verklaringsgrond vir die hele werklikheid beskou word. Hierbo is aangetoon dat Driesch besonderc betekenis aan die sogenaamde "geheelheidskousaliteit" gehey het. Verskeie moderne bioloë, o.a. Von Bertalanffy (1932 en 1949), lê ook groot nadruk op die geheelheidlike aard van organismes. Maar ook buite biologiese kringe het die holistiese filosofie groot aandag getrek. So bv. het Smuts as natuurfilosoof hekendheid verwerf met sy werk: Holism and Evolution (1926). Ek beperk my hier tot 'n kort oorsig van sy idees.

Volgens Smuts bestaan sowel materie as lewe uit eenheidstrukture, die ordelike groepering waarvan natuurlike gehele voortbring, wat liggame of organismes genoem word. Hierdie kenmerk van geheelheid word oral aangetref, en dit 
dui op iets fundamenteels in die heelal. Hy voer die term ,holisme" in om hierdie fundamentele kenmerk van geheelheid aan te dui.

Smuts meen verder dat gehele nie kunsmatige konstruksies van die menslike verstand is nie maar iets reëels in die natuur verteenwoordig; holisme is volgens hom 'n reële, werksame faktor. As stukrag agter die evolusieproses is daar nie 'n vae, kreaticwe impuls of élan vital (soos Bergson (1907) dit genoem het) nie, maar iets wat heel definiticf en spesifiek werksaam is en sodoende die konkrete kosmiese evolusic bewerkstellig.

Die idee van gehele en geheelheid moet nie tot die terrcin van die Biologie beperk word nie, maar is ook van toepassing op anorganiese stowwe en selfs op die hoogste manifestasies van die menslike gees. In die geval van 'n plant of 'n dier kan die fundamenteel holistiese eienskappe daarvan ervaar word as 'n geslote eenheid van die dele, wat so heg is dat die: geheel meer as die som van sy dele is. Die geheel verleen nis alleen 'n besondere struktuur aan die dele nie, maar bepail hulle ook sodanig in hul onderlinge verband dat hul funksics daardeur verander word. Die sintese affekteer en bepaal dic dele sodat hulle tot die behoud van die geheel funksioncer, Die geheel en die dele beïnvloed en bepaal mekaar dus onderling: die geheel is in die dele en die dele in die geheel, on hierdie sintese van die geheel en die dele, word weerspieël in die holistiese aard van die funksies van sowel die dele as dic geheel.

Smuts sien verder 'n progressiewe gradering van die holistiese sintese in die natuur, wat soos volg is: (a) blote fisiese mengsels waar die struktuur onbeduidend is en die delc grotendeels hul afsonderlike eienskappe en funksics lichou; (b) chemiese verbindings, waar die struktuur mecr sinteties is, en die aktiwiteite en funksies sterk deur dic nuwe struktuur beïnvloed word en slegs met groot moeite tot dic individuele dele herlei kan word; (c) organismes, waar 'n nog intensiewer sintese van dic elemente bewerkstellig is, wat 'n stempel van eenheid sterk op die dele of organe afdruk en waaruit 'n stelsel van regulering, koördinasie en sentrale kontrole van die dele en organe voortspruit; (d) Gees (,Mind”) of psigiese organe waar sentrale kontrole, bewustheid, vryheid 
en 'n skeppende vermoë van 'n verreikende aard bereik is; en uiteindelik (e) Persoonlikheid, wat die hoogste, mees ontwikkelde geheel in die heelal is. Dwarsdeur hierdie progressiewe reeks verdiep die aard van die geheelheid. Holisme is derhalwe 'n proses wat nie slegs skeppend is nie maar ook selfskeppend; sy finale struktuur is baie meer holisties as sy beginstrukture. Aangesien holisme 'n proses van skeppende sintese is, is die resulterende gehele nie staties nie maar dinamies, evolusionér en kreatief. Die gehele van evolusie en die evolusieproses sell kan slegs verstaan word in hul betrekking tot hierdic fundamentele eienskap van geheelheid. Die verklaring van die natuur kan derhalwe nie bloot meganies wees nie; die meganistiese opvatting van die natuur het sy plek en regverdiging slegs binne die groter raamwerk van Holisme. Met betrekking tot die organismeryk in die besonder sal die term ,geheel", volgens Smuts, vir die wetenskap baic meer bruikbaar wees as die term "lewe"; dit sal die meganistiese vertolking in 'n groot mate onnodig mak.

Uit hierdie opvattings van Smuts is dit duidelik dat hy holisme as 'n verklaringsheginsel vir die hele werklikheid beskou. Hy maak myns insiens die fout dat hy 'n kenmerk of hoedanigheid van liggame en organismes tot die enigste, alsolute skeppende faktor verhef waardeur die gehele werklikheirl tot stand gekom het. Net soos die materialis die stoflike as algenoegsame verklaring van alles beskou, so verabsoluteer Smuts die holistiese hoedanighede van die dinge. Geheelhej.l beskik oor geen skeppende vermoëns nie, maar is self deel van die skepping. Net soos kleur, massa en so meer is dit bloot 'n eienskap van die nie-lewende sowel as die lewende. Oor dic werklike ard van die lewe leer die holistiese filosofie ons baie min.

\section{Die homplementariteitsbeginsel:}

Nòg die meganisisme, nòg die vitalisme, nòg die holisme bied ons ' $n$ afdoende of hevredigende verklaring van die aard en oorsprong van die lewe. Volgens Lotze en Sihler (1954.) was die fisikus Niels Bohr die eerste om die begrip komplementariteit te gebruik om verskillende beskouings oor die aard van dinge saam te snoer. Volgens die natuurkundiges is ligr gelyktydig golwe en deeltjies; en materic is gelyktydig decl. 
tjies en golwe. Deur die komplementariteitsbegrip word hierdic twee vorms waarin lig en materie tevoorskyn tree, saamgesnoer tot ' $n$ derde wat deur die mens nie geken kan word nic. Dit is ook volgens Bohr van toepassing op die aard van die lewe. Die lewende tree tevoorskyn of in die vorm van fisies-chemiese verskynsels of in die vorm van vitalistiese, psigiese en geheclheidlike verskynsels. Om albei hierdie fasette in één geheelbecld te begryp, is nie moontlik nie omdat dit dic mens se begripsvermoë te howe gaan. Elkeen van die twec heelde gee ook die werklikheid nie volledig weer nie, en die een beeld mag nie met die ander vermeng word nie. Agter die twee komplementêre beelde is daar 'n derde wat nie met die verstand ,gevat" kan word nie. Hierdie insig bring ons aan die grense van die kenbare. Volgens Lotze en Sihler (1954) moet die natuurwetenskap, wat hom met die kenbare, rasionaliseerbare faset van die werklikheid besig hou, hier in heskeidenheid die grens vir sy wetenskapsbeocfening trek.

Net soos Hartmann (1933) is Lotze en Sihler (1954) dus die mening toegedaan dat daar 'n faset van die lewende is wat irrasioneel, d.w.s. bo die menslike begripsvermoë is. Hiertecn kan die beswaar gemaak word dat menige problecm wat vroec̈r nie deurgrond kon word nie en selfs as onoplosbaar beskou is, tog later met dic kousale navorsing verklaar kon word. Dat dit so is, kan nie weerlê word nie. En dit is sekerlik ook so dat die wetenskap nooit sy soeke na dic waarheid mag staak nic. Dit moet steeds sy taak bly om die kenbare gedeelte van dic werklikheid soveel moontlik te verstaan en dit van die onkenbare te onderskei. In 'n wetenskap van die lewende wat hom van sy beperkings bewus is, is daar egter altyd plek vir dis onbegryplike, die misterie en die wonder. En die bioloog wat so 'n wetenskap beoefen, bly steeds met diepe ontsag vir dic wonderbaarlike grootsheid van die skepping vervul.

P.U. vir C.H.O.

P. J. Botha.

\section{IITERATUURVERWYSINGS}

1. Bergson, HI. (1907): L'évolution créatice. F. Alcan, Parys. (Oorsig in Joad, 1948).

2. Bertalanffy, I. von (1932): Theoretiche Biologie. Gebrüder Borntracger, Berlyn. 
3. Bertalanffy, L. von (1949): Das Biologische Weltbild. A. Francke, Bern.

1. Driesch, H. (1922): Geschichte des Vitalismus. J. A. Barth, Leipzig.

5. Hartmann, M. (1925): Biologie und Philosophie. J. Springer, Berlyn.

6. Hartmann, M. (1933): Allgemeine Biologie. Fischer, Jena.

i. Hartmann, M. (1948): Die philosophischen Grundlagen der Naturwissenschaften. Fisher, Jena.

8. Hartmann, M. (1956): Einfïhrung in die allgemeine Biologie. Sammlungr Göschen, Bd. 96. Berlyn.

9. IIuxley, J. (1919): Soviet Genetics and World Science. Iondon.

10. Joad, C. E. M. (1948): Guide to Philosophy. V. Gollancz, London.

11. Lotze, R. en Sihler, H. (1954): Das Weltbild der Natuurwissenschaft. J. B. Metzler, Stuttgart.

12. Simpson, G. G. (1952): The Meaning of Evolution. New Haven.

13. Smuts, J. C. (1926): Holism and Evolution. Macmillan, London. 